\title{
The Ion Propulsion System for the Asteroid Redirect Robotic Mission
}

\author{
Daniel A. Herman, ${ }^{1}$ Walter Santiago, ${ }^{2}$ and Hani Kamhawi ${ }^{3}$ \\ NASA Glenn Research Center, Cleveland, Ohio, 44135, United States \\ and
}

James E. Polk, ${ }^{4}$ John Steven Snyder, ${ }^{5}$ Richard R. Hofer, ${ }^{6}$ and Michael J. Sekerak ${ }^{7}$

Jet Propulsion Laboratory, California Institute of Technology, Pasadena, CA, 91109

\begin{abstract}
The Asteroid Redirect Robotic Mission is a Solar Electric Propulsion Technology Demonstration Mission (ARRM) whose main objectives are to develop and demonstrate a high-power solar electric propulsion capability for the Agency and return an asteroidal mass for rendezvous and characterization in a companion human-crewed mission. This high-power solar electric propulsion capability, or an extensible derivative of it, has been identified as a critical part of NASA'a future beyond-low-Earth-orbit, human-crewed exploration plans. Under the NASA Space Technology Mission Directorate the critical electric propulsion and solar array technologies are being developed. This paper presents the conceptual design of the ARRM ion propulsion system, the status of the NASA in-house thruster and power processing development activities, the status of the planned technology maturation for the mission through flight hardware delivery, and the status of the mission formulation and spacecraft acquisition.
\end{abstract}

$\begin{array}{ll} & \\ \text { AEPS } & =\text { Advanced Electric Propulsion System } \\ \text { ARCM } & =\text { Asteroid Redirect Crewed Mission } \\ \text { ARM } & =\text { Asteroid Redirect Mission } \\ \text { ARRM } & =\text { Asteroid Redirect Robotic Mission } \\ \text { ARV } & =\text { Asteroid Redirect Vehicle } \\ \mathrm{BaO} & =\text { Barium Oxide } \\ \mathrm{DRO} & =\text { Distant Retrograde Orbit } \\ \mathrm{EDU} & =\text { Engineering Development Unit } \\ \mathrm{EP} & =\text { Electric Propulsion } \\ \text { FM } & =\text { Flight Model } \\ \text { FT } & =\text { Flight Thruster }\end{array}$

${ }^{1}$ Ion Propulsion System (IPS) Lead, Electric Propulsion Systems Branch, 21000 Brookpark Rd., MS 162-3, AIAA Associate Fellow, daniel.a.herman@nasa.gov.

${ }^{2}$ IPS Power Processing Lead, Power Management and Distribution Branch, 21000 Brookpark Rd., MS 333-1.

${ }^{3}$ IPS Deputy Thruster Lead, Electric Propulsion Systems Branch, 21000 Brookpark Rd., MS 301-3, AIAA Associate Fellow.

${ }^{4}$ IPS Deputy Lead, Propulsion, Thermal, and Materials Engineering Section, 4800 Oak Grove Drive, MS 125-109, AIAA Associate Fellow.

${ }^{5}$ IPS System Engineering Lead, Electric Propulsion Group, 4800 Oak Grove Drive, MS 125-109, AIAA Senior Member.

${ }^{6}$ IPS Thruster Lead, Electric Propulsion Group, 4800 Oak Grove Drive, MS 125-109, AIAA Associate Fellow.

${ }^{7}$ Plasma Diagnostics Package Lead, Electric Propulsion Group, 4800 Oak Grove Drive, MS 125-109, Senior AIAA Member. 


$\begin{array}{ll}\text { GRC } & \text { Glenn Research Center } \\ \text { HERMeS } & =\text { Hall Effect Rocket with Magnetic Shielding } \\ \text { IPS } & =\text { Ion Propulsion Subsystem } \\ \text { JPL } & =\text { Jet Propulsion Laboratory } \\ \text { LaB }_{6} & =\text { Lanthanum Hexaboride } \\ \text { LDRO } & =\text { Lunar Distant Retrograde Orbit } \\ \text { MOSFET } & =\text { Metal-oxide-semiconductor field-effect transistor } \\ \text { MIH } & =\text { Mechanical Integration Hardware } \\ \text { NEA } & =\text { Near-Earth Asteroid } \\ \text { PDP } & =\text { Plasma Diagnostics Package } \\ \text { PMA } & =\text { Propellant Management Assembly } \\ \text { PPU } & =\text { Power Processing Unit } \\ \text { REU } & =\text { Remote Engineering Unit } \\ \text { SCB } & =\text { System Control Board } \\ \text { SEP } & =\text { Solar Electric Propulsion } \\ \text { SLS } & =\text { Space Launch System } \\ \text { STMD } & =\text { Space Technology Mission Directorate } \\ \text { TDM } & =\text { Technology Demonstration Mission } \\ \text { TDU } & =\text { Technology Demonstration Unit } \\ \text { TGA } & =\text { Thruster Gimbal Assembly } \\ \text { XFC } & =\text { Xenon Flow Controller } \\ \text { QM } & =\text { Qualification Model }\end{array}$

—OR missions beyond low Earth orbit, spacecraft size and mass can be dominated by onboard chemical propulsion 1 systems and propellants that may constitute more than 50 percent of spacecraft mass. This impact can be substantially reduced through the utilization of Solar Electric Propulsion (SEP) due to its substantially higher specific impulse. Studies performed for NASA's Human Exploration and Operations Mission Directorate and Science Mission Directorate have demonstrated that a $50 \mathrm{~kW}$-class SEP capability can be enabling for both near term and future architectures and science missions. ${ }^{1}$ A high-power SEP element is integral to the Evolvable Mars Campaign, illustrated in Fig. 1, which presents an approach to establish an affordable evolutionary human exploration architecture. ${ }^{2}$ To enable SEP missions at the power levels required for these applications, an in-space demonstration of an operational 50 kW-class SEP spacecraft has been proposed as a SEP Technology Demonstration Mission (TDM). In 2010 NASA's Space Technology Mission Directorate (STMD) began developing large, deployable photovoltaic solar array structures for high-power electrical power production and high-power electric propulsion technologies. ${ }^{3-8}$ The maturation of these critical technologies has made mission concepts utilizing high-power SEP viable.

The Asteroid Redirect Robotic Mission (ARRM) utilizes an SEP spacecraft to return up to 20 metric tons (up to 6 m maximum extent) of asteroidal mass from the surface of a larger asteroid, to a stable orbit around the Moon for subsequent access by a human crewed mission. ${ }^{9-13}$ The Ion Propulsion System (IPS) for ARRM will be used for heliocentric transfer from Earth to the target asteroid, orbit capture at the asteroid, transfer to a low orbit about the asteroid, a planetary defense demonstration after retrieval of asteroidal mass from the larger asteroid, departure and escape from the asteroid, the heliocentric transfer from the asteroid to lunar orbit, and insertion into a lunar distant retrograde orbit. In addition, the IPS will provide pitch and yaw control of the spacecraft during IPS thrusting. The technology development, led by the NASA Glenn Research Center and the Jet Propulsion Laboratory, has been focused on maturation of the high-power Hall thruster and power

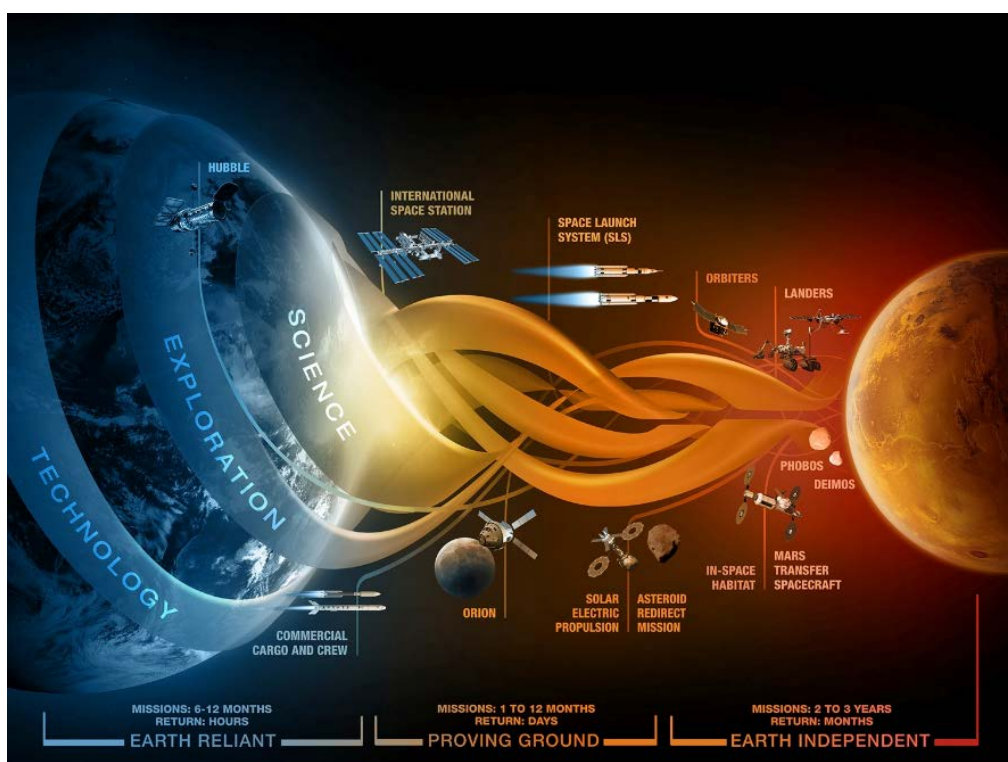

Figure 1. Evolvable Mars Campaign (EMC) graphical depiction. 
processing unit. This work had recently begun the transition to a commercial vendor for the development of an Engineering Development Unit (EDU) EP string and optional Qualification Model (QM) and Flight Model (FM) hardware delivery in a timeline consistent with the current ARRM implementation. The flight electric propulsion string hardware will be provided as government furnished equipment to the Asteroid Redirect Vehicle (ARV) commercial spacecraft provider.

\section{Mission and Spacecraft Overview}

The reference ARRM mission description, shown in Fig. 2, is planned for a Dec. 2021 launch date with a 2026 asteroid boulder return to cis-lunar space. The reference ARRM target asteroid is $2008 \mathrm{EV}_{5}$, which is a volatile rich, type-C asteroid. The ARRM mission has alternate candidate asteroids and mission, and the ion propulsion subsystem is being developed with sufficient capability for alternate targets and mission scenarios.

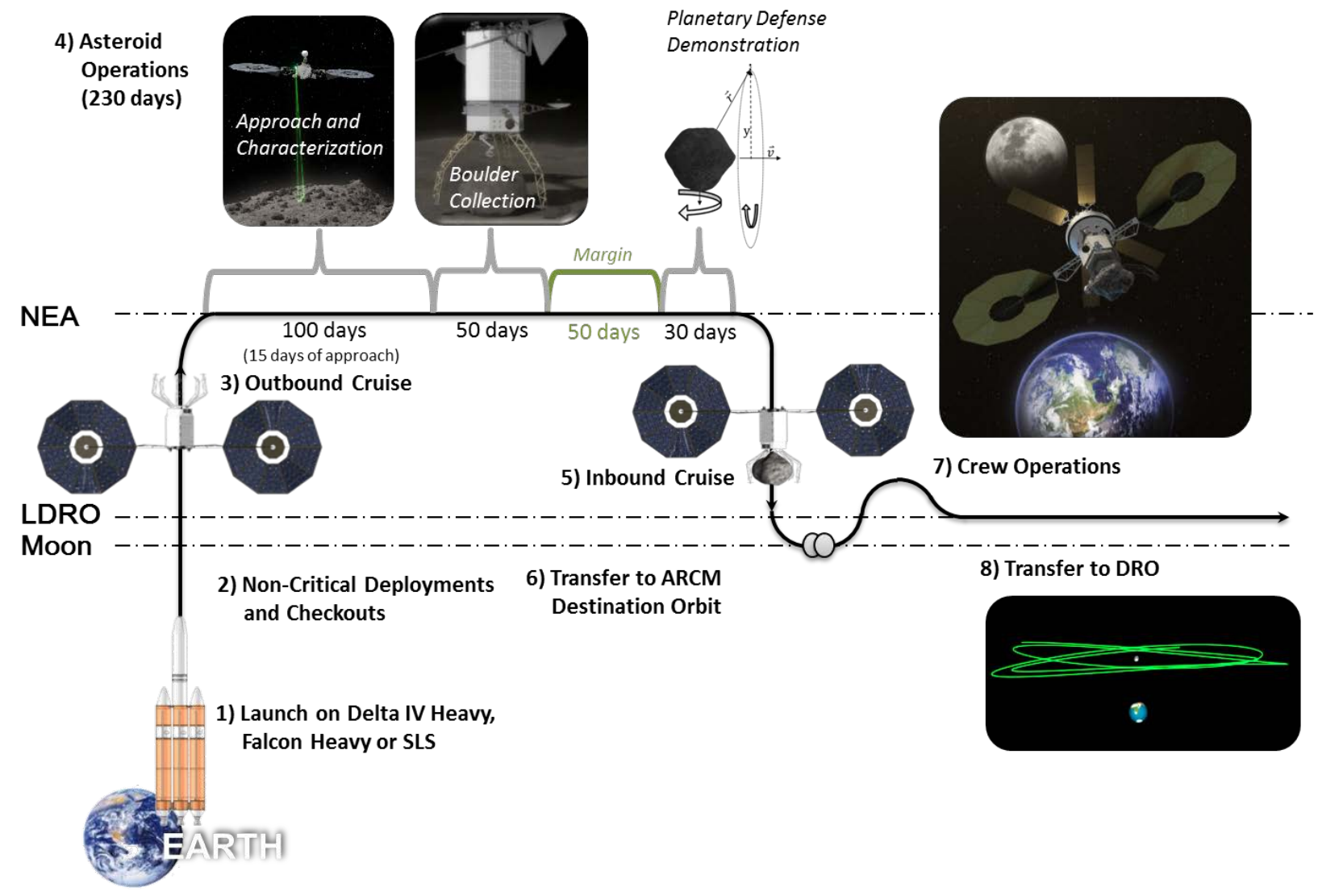

Figure 2. ARRM Mission Overview

\section{A. Asteroid Redirect Vehicle (ARV) Conceptual Design}

NASA has developed an in-house reference Asteroid Return Vehicle (ARV) detailed conceptual design to prove feasibility and derive requirements for ARRM. This ARV concept relies on several key technology areas including: high-efficiency, high-power solar arrays; high-power, high-throughput electric propulsion; autonomous, deep-space proximity operations; and deep-space rendezvous sensors and docking capabilities. The conceptual ARV design in Fig. 3 shows both MegaFlex and ROSA solar array concepts on the vehicle because either solar array technology could perform the mission. The NASA ARV design is divided into two modules: a spacecraft bus that hosts core spacecraft housekeeping functions, GN\&C, and SEP and a capture module that hosts functions for capturing the asteroid boulder. The reference ARV leverages synergy with the Restore-L (mid-2020 planned launch) servicing mission for the capture module, the rendezvous and proximity operations sensors, hybrid flight computing algorithms, servicing avionics, and dexterous robotics. 
The IPS-related elements of the NASA ARV design include 4 large metal-lined, composite-overwrapped propellant tanks (vehicle has the capability to house up to 8) capable of storing in excess of 5 tons of xenon propellant with a vehicle capability (by putting tanks in the 4 additional open bays) in excess of 10 tons of xenon. The power processing units are mounted directly to heat-pipe radiators (shown in green on Fig. 3) on the same sides of the spacecraft as the solar arrays to minimize direct solar flux. The thrusters are mounted on individual deployable booms that reduce the impact of thruster plume interactions with the solar arrays and docking mechanism (on the aft end of the spacecraft) and provide large-angle thrust vector control for the planetary defense demonstration.

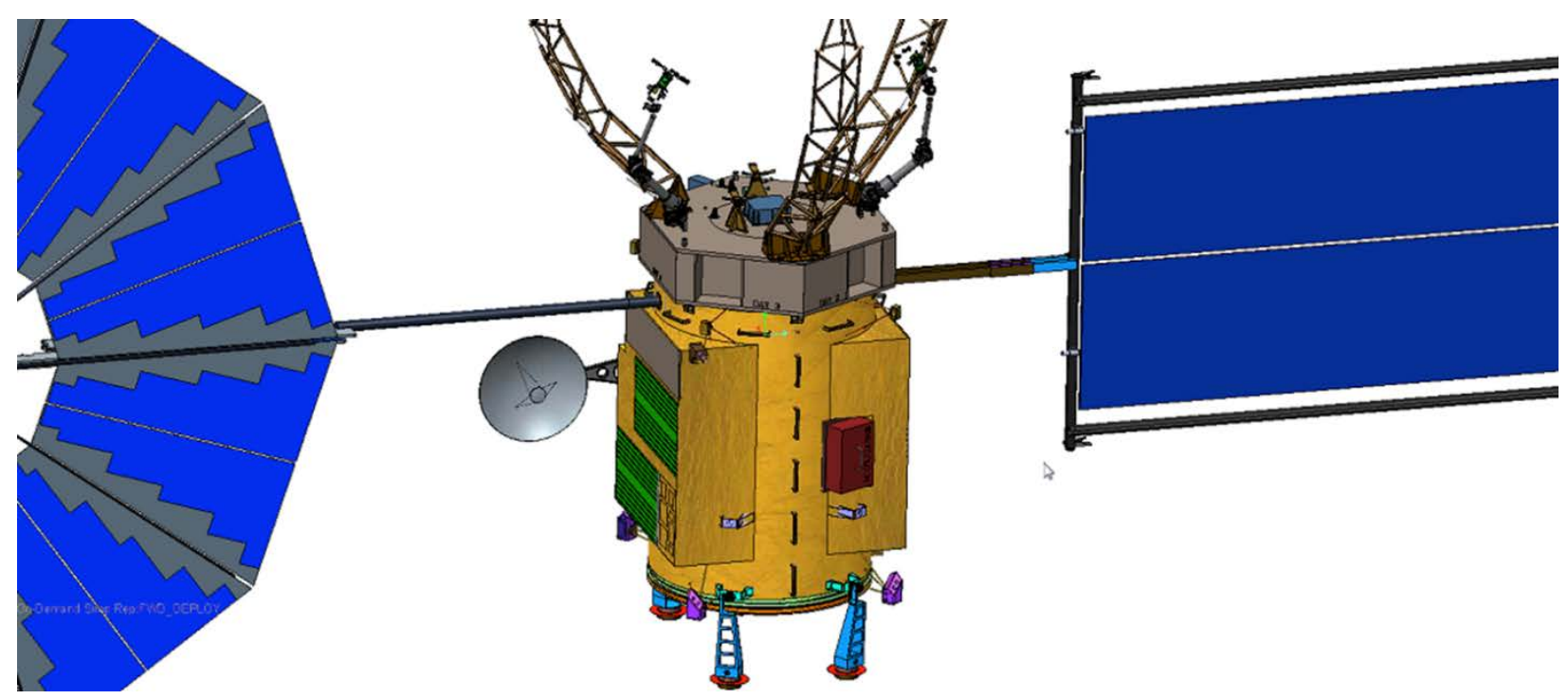

Figure 3. Reference Asteroid Return Vehicle (ARV) Concept Rendering.

\section{B. ARRM Plasma Diagnostics Package (PDP) Implementation}

A flight plasma diagnostics package (PDP) is being planned for ARRM to provide the data needed to validate models of high-power SEP operation and spacecraft plasma interactions, design tools that are critical for enabling high-power SEP spacecraft to support future human and robotic missions to Mars. The PDP in-flight measurements allow characterization of the plasma environment as well as SEP system performance measurements. The PDP will provide flight plasma spacecraft interaction data that cannot be accurately assessed by ground test plasma measurements. The PDP will measure the plasma environment, surface erosion, material re-deposition, and serve as a tool for thruster characterization. The government-led development of the PDP will be provided flight hardware to the spacecraft prime contractor as government-furnished equipment. An initial concept for the plasma diagnostics package, shown in Fig. 4, utilizes high heritage instruments flown on prior NASA and other government spacecraft. ${ }^{14}$ 

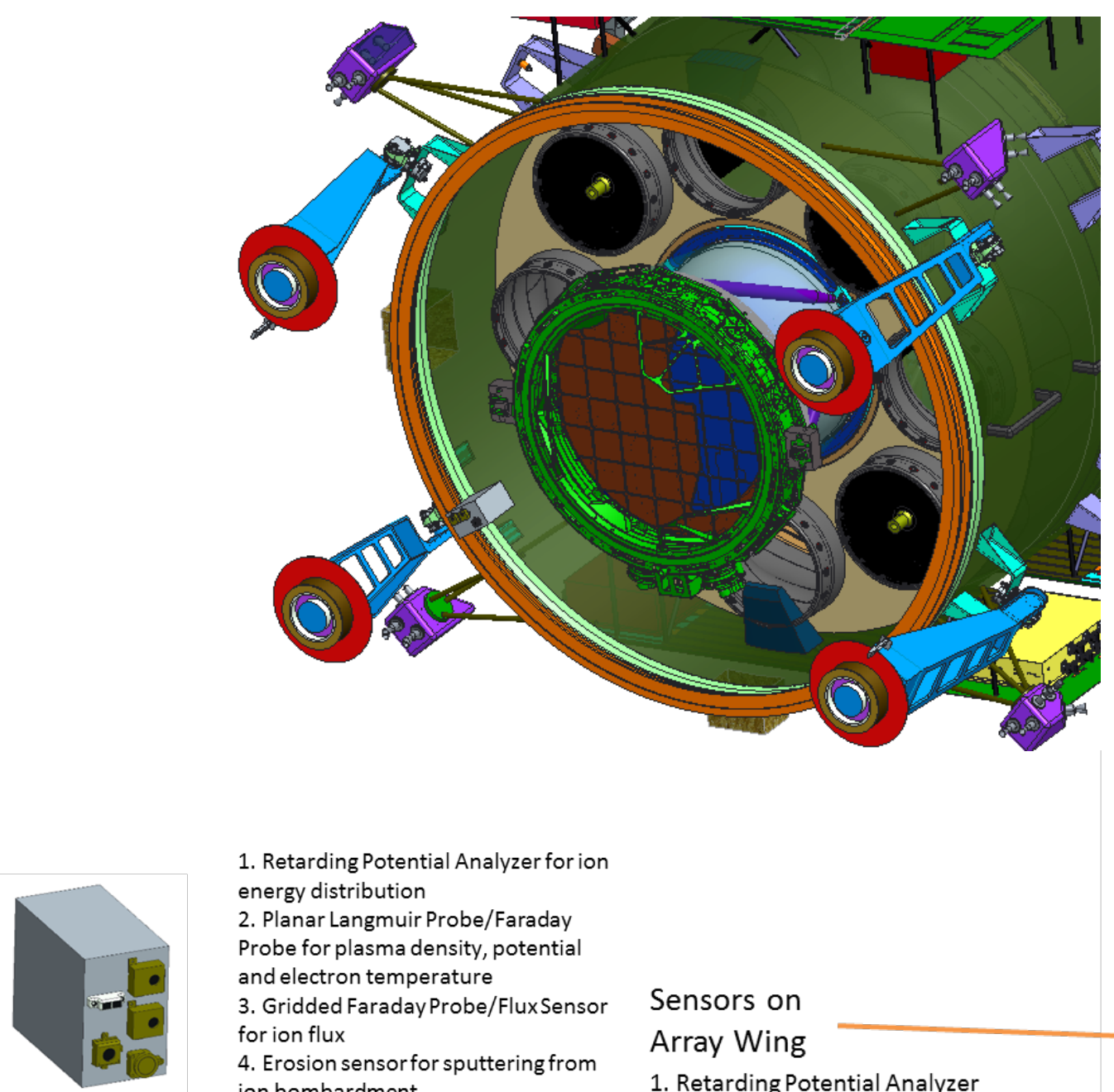

1. Retarding Potential Analyzer for ion energy distribution

2. Planar Langmuir Probe/Faraday Probe for plasma density, potential and electron temperature

3. Gridded Faraday Probe/FluxSensor for ion flux

4. Erosion sensor for sputtering from ion bombardment

5. Photometer tor deposition of sputtered material

\section{Sensors on} Array Wing

1. Retarding Potential Analyzer

2. Planar Langmuir Probe/Faraday Probe

3. Erosion sensor

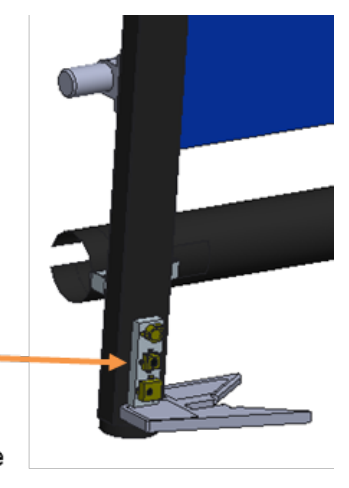

Figure 4. Conceptual ARRM Plasma Diagnostics Package (PDP) Implementation

\section{Ion Propulsion System Description}

The key driving requirements for the ARRM IPS, shown in Table 1, are that it must be single fault tolerant while processing up to $5,000 \mathrm{~kg}$ of xenon over an input power range of 6.67 to $40 \mathrm{~kW}$ with input voltages ranging from 95 to $140 \mathrm{~V}$ and an operation life of at least seven years. The required propellant throughput capability of the IPS is 5,000 $\mathrm{kg}$, by far the largest propellant throughput processed by an electric propulsion system.

Table 1. Key ARRM Requirements for the Ion Propulsion System.

\begin{tabular}{|lc|}
\hline Capability & Value \\
\hline Total system power & $40 \mathrm{~kW}$ \\
\hline Maximum specific impulse & $2600 \mathrm{~s}$ \\
\hline Xenon throughput & $5,000 \mathrm{~kg}$ \\
\hline String fault tolerance & Single \\
\hline Solar range & $0.8-1.7 \mathrm{AU}$ \\
\hline Input voltage range & $95-140 \mathrm{~V}$ \\
\hline
\end{tabular}


As the ARRM mission has matured, the IPS required capabilities have evolved. The decision that selected the capture and return of an asteroid boulder from a larger asteroid versus returning an entire small asteroid led to a reduced maximum heliocentric distance from 1.9 to 1.7 A.U. The decision to procure the ARV from industry along with a more mature mission design, led to a reduction in the ARRM required throughput from 10 tons to 5 tons of xenon. Mission analyses performed with simplified throttle curves for most-probable ARRM scenarios showed that the returned asteroid boulder mass and propellant required are insensitive to the maximum specific impulse over the range of $2600-3000$ s. Specifically, the maximum returnable mass and xenon propellant required varied by less than $5 \%$ and $2 \%$, respectively. As a result the ARRM IPS throttling used by mission design has been simplified. Mission design by using a constant-current power throttle table for performing trajectory analyses. For the ARRM planetary defense demonstration, a reduced thrust is required that can be accomplished by gimballing thrusters to large angles and/or throttling to lower levels. For the planetary defense demonstration, mission design is utilizing a $3.1 \mathrm{~kW}, 200$ $\mathrm{mN}$ thrust operating point, which roughly would correspond to $300 \mathrm{~V}$ and 10.4 A discharge voltage and current, as the minimum power operating condition. Combined, ARRM mission design is utilizing: constant discharge current (20.8 A) power throttling between $300 \mathrm{~V}-600 \mathrm{~V}$ discharge voltages, constant discharge voltage (300 V) power throttling between $10.4-20.8$ A discharge currents, and a single planetary defense operating point at $300 \mathrm{~V}$ discharge voltage and 10.4 A discharge current. The anticipated performance for the single string throttling described above is illustrated in Table 2.

Table 2. ARRM Mission Design - EP String Performance

\begin{tabular}{|ccccc|}
\hline $\begin{array}{c}\text { EP String Total } \\
\text { Input Power (kW) }\end{array}$ & $\begin{array}{c}\text { Discharge } \\
\text { Voltage (V) }\end{array}$ & $\begin{array}{c}\text { Thrust (mN) } \\
\text { Mate (mg/s) }\end{array}$ & $\begin{array}{c}\text { System } \\
\text { Efficiency }\end{array}$ \\
\hline 13.3 & 600 & 589 & 22.9 & 0.57 \\
\hline 11.1 & 500 & 519 & 22.0 & 0.55 \\
\hline 8.9 & 400 & 462 & 22.1 & 0.54 \\
\hline 6.7 & 300 & 386 & 21.7 & 0.52 \\
\hline 3.4 & 300 & 200 & 11.9 & 0.49 \\
\hline
\end{tabular}

\section{Electric Propulsion String Functional Description}

A high-level block diagram of the ARV IPS has been previously provided for the NASA in-house spacecraft conceptual design in Ref. 15. While the in-house ARV retains the capability of storing up to 10 tons of xenon in 8 xenon tanks, only 4 are now required in order to meet the reduced 5 ton useable xenon mission requirement. The IPS consists of 4 identical electric propulsion strings. An electric propulsion string, defined in Fig. 5, is comprised of the following four elements:

1. Flight Thruster (FT).

2. Power Processor Unity (PPU).

3. Xenon Flow Controller (XFC).

4. Interconnecting Cable Harnesses.

The ARV IPS includes four flight electric propulsion (EP) strings, the high-pressure portion of the xenon feed system, and the Mechanical Integration Hardware (MIH) including cabling. The xenon feed system consists of the xenon tanks, a propellant management assembly, and the xenon flow controllers. Each EP string is operated independently of the others by the spacecraft. Single fault tolerance is achieved through block-redundancy at the EP string level with internal redundancy for the xenon feed system components outside of the EP strings. Depending upon the ARV spacecraft prime selection and their implementation approach, the 2-axis thruster gimbal assembly may be included in the ARV IPS or included in the Structures and Mechanisms System.

A major challenge for the development of the electric propulsion system is determining how to appropriately manage the interfaces of the electric propulsion string elements, which need to be defined for the Advanced Electric Propulsion System (AEPS) contract ahead of the selection of the spacecraft prime and the final ARV design. An example of this concern is the interface between the Hall thruster and the flight gimbal where mechanical integration is non-trivial and where launch load amplification/attenuation through the gimbal to the Hall thruster can alter the loads observed at the thruster. ${ }^{16,17}$ The NASA in-house ARV design has been used to guide the definition of these 
interfaces and appropriate launch loads for AEPS. These will continually be monitored as the actual ARV design is matured.

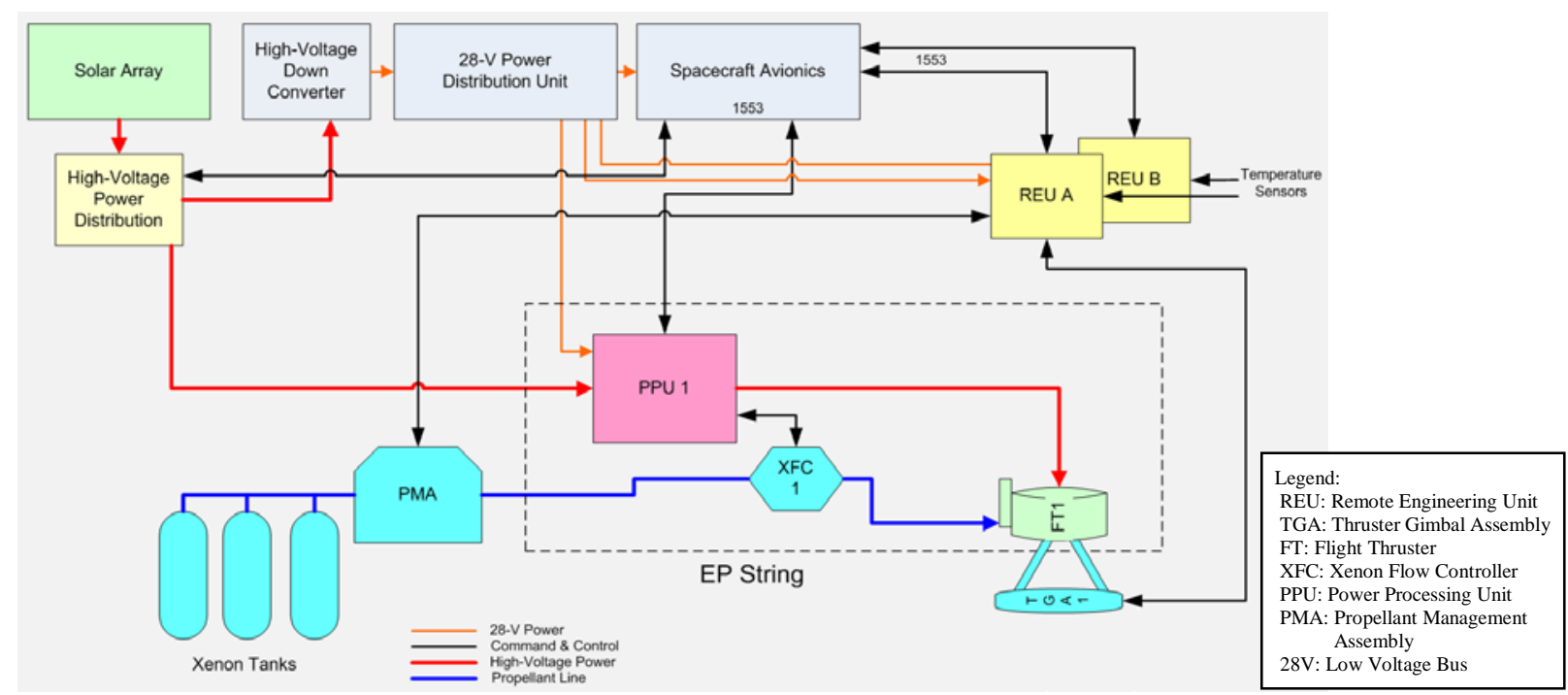

Figure 5. Electric Propulsion String Defined by Elements within Dotted Lines

\section{NASA In-House Electric Propulsion Development}

In 2010 NASA's Space Technology Mission Directorate (STMD) began developing large, deployable photovoltaic solar array structures for high-power electrical power generation and high-power electric propulsion technologies. ${ }^{3-8}$ The maturation of the critical technologies required for the high-power SEP vehicle has made mission concepts utilizing high-power SEP viable. ${ }^{18}$ The high-power electric propulsion investments were in areas having high technical risks and/or long-lead times. NASA in-house development of the $12.5 \mathrm{~kW}$ Hall Effect Rocket with Magnetic $\underline{\text { Shielding }}$ (HERMeS) thruster and HP-120V/800V power processing unit (PPU) have resulted in two high-fidelity development model thrusters and a brass-board power processing unit that have been extensively tested and characterized separately as well as demonstrated as an integrated system. There has been no direct development work for the xenon feed controller because it is low-risk and does not require a long development as a result of multiple options available utilizing flight qualified components. The NASA development work validated subsystem design methodologies, developed critical diagnostics, demonstrated performance that meets current mission requirements, made significant strides in life qualification, developed and validated an array of models, and potentially provided a point-of-departure design for the contracted technology maturation and flight system development with industry. The conceptual design of the IPS components for the current ARV concept is described below.

Desired EP string performance for ARRM at beginning-of-life was shown in Table 2. The table utilizes the current best estimates from the in-house $12.5 \mathrm{~kW}$ thruster and PPU based on demonstrated performance. The desired flight electric propulsion string for ARRM should meet or exceed the performance in Table 2 while simultaneously meeting the ARRM lifetime requirement over all environmental conditions and input voltages. 


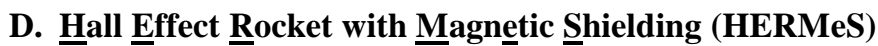

The conceptual ARV IPS design utilizes a $12.5 \mathrm{~kW}$ magnetically-shielded Hall thruster. To demonstrate highpower, high-specific-impulse performance for the desired mission capability and required lifetime, a joint NASA Glenn Research Center and Jet Propulsion Laboratory team developed the $12.5 \mathrm{~kW}$ Hall Effect Rocket with Magnetic Shielding (HERMeS). To demonstrate that HERMeS meets the desired specification and to reduce several key risks associated with the thruster, two Technology Demonstration Units (TDUs) were fabricated and tested. HERMeS is unique because it is the first Hall thruster designed for magnetic shielding over its entire service life. The design of HERMeS incorporates technologies developed by NASA over nearly two decades, and is enabled through the use of magnetic shielding to effectively eliminate discharge chamber erosion. ${ }^{4,19-21}$ The result is a significant increase in the operational lifetime of state-of-the-art for Hall thrusters, with HERMeS being designed to operate at $3000 \mathrm{~s}$ specific impulse with a lifetime exceeding $50 \mathrm{kh}$. These capabilities exceed the current requirements for ARRM. The methodology used to design HERMeS emphasized the use of thermal, structural, and physics-based plasma modeling that were used in nearly every aspect of the thruster design to achieve its design goals. ${ }^{20,22}$ The design of HERMeS resulting from this approach uses an integrated magnetic and thermal design, pole piece covers, a graphite cathode keeper, an internally mounted cathode, and a downstream-plenum gas distributor.

The HERMeS development plan was formulated from a set of technical risks that could impact mission success. ${ }^{15}$ Each element of the development plan is traceable to these risks. The Hall thruster development for ARRM consists of three major hardware build phases: the Technology Development Unit (TDU), Engineering Development Unit (EDU), and the combined Qualification Model (QM) and Flight Model (FM) phases. HERMeS is now in the TDU phase, which is scheduled to complete by mid-2016, and the project is on track to complete all of its planned tasks prior to the EDU phase starting. The EDU phase will be initiated under the Advanced Electric Propulsion String (AEPS) contract that includes an option for the QM/FM hardware phase.

HERMeS Technology Demonstration Unit 1 (TDU-1) was fabricated and completed the first test campaign of its performance, stability, thermal, and wear characteristics in 2015. TDU-1 thruster is shown operating in VF5 at NASA GRC in Fig. 6. The first test campaign demonstrated thruster performance, verified magnetically shielded operation at high specific impulse, and affirms that the internally mounted cathode minimizes the effects of facility pressure on performance. Details regarding TDU thruster design, mission-required operating envelope, and test results are detailed in Refs. 4, 19, 20, and 2228.

The second test campaign for TDU-1 has concentrated on characterizing TDU-1 in different test conditions to determine which is most appropriate for extended operation both onorbit and during the ground test and subsequent extended wear characterization of the thruster. The objectives of the TDU- 1 wear test are to measure thruster component erosion rates used to

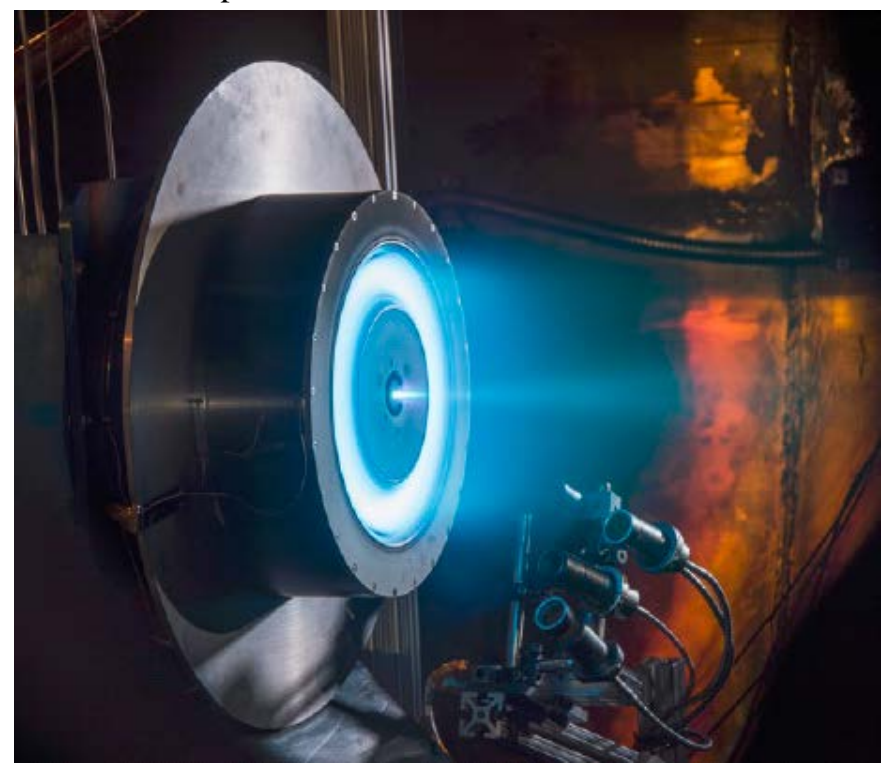

Figure 6. 12.5kW Hall-Effect Rocket with Magnetic Shielding (HERMeS) operating in VF5 at NASA GRC. validate thruster erosion model predictions, demonstrate an operating duration on the order of 2,000 hours, and determine any unexpected/unknown thruster failure or wear-out mechanisms. As of June 23, 2016, TDU-1 has accumulated 728 hours of operation with the predominate amount of time at $12.5 \mathrm{~kW}, 600 \mathrm{~V}$ discharge power and voltage, respectively. Details regarding the motivation and testing of TDU-1 in different test conditions and during the wear test can be found in Refs. 29 - 36.

A second thruster, TDU-2, was fabricated for an environmental testing campaign. Models were used to identify features of the TDU design that required modifications to increase the factor of safety to a level appropriate for qualification-level vibration, shock, and thermal-vacuum testing. The major TDU-2 modifications made were: the use of a reinforced radiator for added structural rigidity, improved thermal conductance from the discharge channel to the radiator, increased pre-load on the mechanism that retains the discharge channel, and more robust fasteners. The TDU2 environmental testing campaign is planned to be completed in September 2016. ${ }^{37}$ 
Component development work has been performed on the HERMeS hollow cathode. Two technologies with different emitter materials have been matured in parallel. Testing of laboratory Barium Oxide (BaO) and Lanthanum Hexaboride $\left(\mathrm{LaB}_{6}\right)$ hollow cathodes has included extensive thermal and plasma characterizations, wear testing, and (for $\mathrm{LaB}_{6}$ ) cyclic heater testing. A cathode downselect is planned for June 2016. ${ }^{38-40}$

\section{E. Power Processor Unit (PPU)}

To demonstrate high-power, high-specific-impulse system performance for the desired mission capability and reduce several key electric propulsion system risks, the NASA Glenn Research Center developed the Brassboard HP120V Power Processing Unit (PPU). The HP-120V PPU converts power from the 95 - 140 V spacecraft solar arrays into the currents and voltages needed to start and operate the thruster. The PPU also communicates with the spacecraft and controls the xenon flow controller. The overall strategy for the NASA in-house power converter electronic design utilizes a full-bridge topology on the discharge supply modules and half-bridge topology for the magnet supplies. These topologies are good for high power applications because it has low electrical stress on the power transistors with efficient transformer utilization. Metal-oxide-semiconductor field-effect transistors (MOSFETs) are paralleled as needed on each leg of the bridge to reduce conduction losses on the transistors. A full bridge topology is also used for the auxiliary supplies to allow for ample room for growth and to be able to reuse control and gate drive printed wiring boards.

Initially for the NASA-developed HP-120V PPU, breadboard circuits for the discharge and auxiliary supplies power converter were built and tested. These were used to evaluate and optimize the controls, the main power transformer, output inductor, and gate drive circuit design. Subsequently, the optimized design was then used to develop a brassboard PPU capable of operating in vacuum, but without the final form and fit of a flight PPU. This allows the PPU to operate in simulated operational environments in order to assess critical performance functions. The overall strategy for thermal design was to locate components with the highest dissipation like transformers, inductors, MOSFETs and diodes with a direct thermal path to the baseplate for good heat sink. Printed circuit boards have thermal planes and are mounted vertically to aluminum brackets that removed heat from the perimeter of the PCB into the baseplate.

The PPU processes electrical power from high voltage solar arrays and a $28 \mathrm{~V}$ unregulated, battery-backed bus. The brassboard unit powers a high power Hall thruster from 2 to $14 \mathrm{~kW}$ of discharge power and provides auxiliary outputs for inner and outer magnets, cathode keeper and heater. The discharge supply in this PPU is capable of supplying up to $800 \mathrm{~V}$ for specific impulse of 3,000 s and up to $14 \mathrm{~kW}$ of discharge power. The discharge supply consists of four discharge modules that may operate at a maximum of $3.5 \mathrm{~kW}$ each. The output current of each discharge module is limited to $20 \mathrm{~A}$. Each discharge module can provide an output voltage of up to $200 \mathrm{~V}$ and the outputs are stacked in series to generate the required $800 \mathrm{~V}$ output as shown in Fig. 7. When the required output voltage is lower than $400 \mathrm{~V}$, two of the four discharge modules can be disabled by command to increase loading and improve performance. Bypass

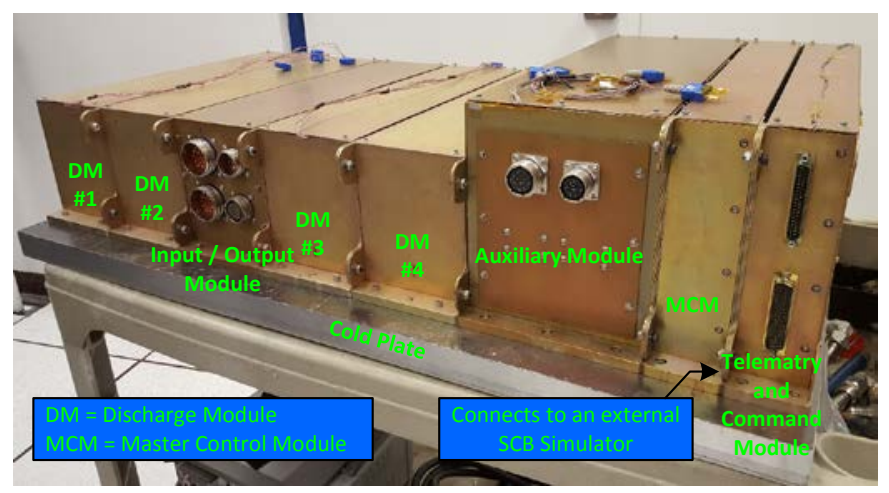

Figure 7. 14kW HP-120/800V Brassboard PPU. diodes were included to further improve performance when operating in this mode.

This project fabricated and tested a high power, high performance PPU design. Modeling with physics-based thermal and circuit models was performed to support the development and testing. The testing included electrical performance and thermal characterization using resistive and thruster loads, in ambient and vacuum conditions. The 120V PPU discharge supply demonstrated a peak efficiency of $95.8 \%$ and higher than $94 \%$ efficiency down to $30 \%$ of the maximum output power. ${ }^{41}$ With the magnet and keeper supplies operating at levels representative of the thruster, the PPU demonstrated total efficiencies as high as $95 \%$ at $100 \mathrm{~V}$ input, $12.5 \mathrm{~kW}$ discharge power, and $700 \mathrm{~V}$ discharge voltage. After completion of benchtop testing, the HP-120V PPU was tested twice in ambient with the HERMeS thruster in VF5 at NASA GRC demonstrating the capability to start and operate a dynamic thruster load over the full range of HP-120V specifications including the $12.5 \mathrm{~kW}$, 3000s specific impulse thruster design point. Following successful completion of the ambient and thruster integration tests, the HP-120V PPU was characterized in vacuum. The results from the HP-120V PPU tests can be found in Refs. 41 and 42.

In parallel to the HP-120V PPU development at NASA GRC, a System Control Board (SCB) was developed at JPL to handle the communication with the spacecraft, operate the XFC, control the PPU outputs, and provide fault 
protection. The system control board is the PPU (and EP string) interface with the spacecraft computer, taking commands and sending status. A prototype SCB has been fabricated and is undergoing functional testing before integration with the HP-120V PPU. A schematic of the system control board interfaces is shown in Fig. 8.

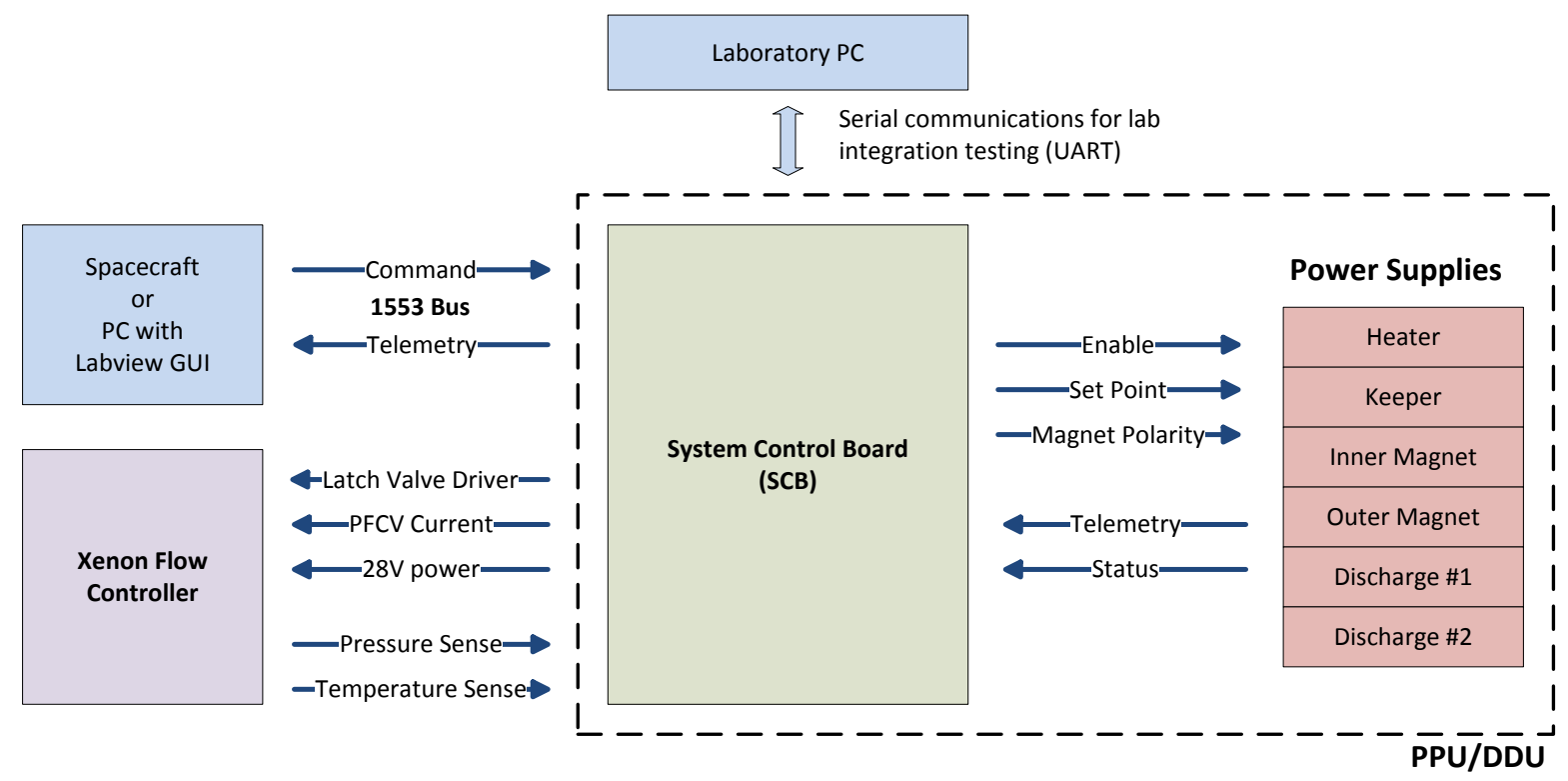

Figure 8. System Control Board Interfaces.

\section{Advanced Electric Propulsion System and Asteroid Redirect Vehicle Transition to Flight}

The acquisition of the Advanced Electric Propulsion System (AEPS) was initiated for engineering development and subsequent system qualification and flight unit fabrication in order to meet the required flight hardware delivery dates for ARRM. Similarly, the acquisition of the Asteroid Redirect Vehicle (ARV) for ARRM was initiated.

\section{F. Advanced Electric Propulsion System Contract}

Given the lead times required for the development and fabrication of the electric propulsion strings, the Advanced Electric Propulsion System contract was initiated on May 5, 2015 with the draft RFP release. The competitivelyselected cost-plus fixed fee including incentives contract consists of the development of an Engineering Development Unit (EDU) EP string and optional Qualification Model (QM) and Flight Model (FM) hardware delivery within three years. ${ }^{43}$ This contract includes the thrusters, power processing units, xenon flow controllers, and electric harnesses between the subsystems. The contract was awarded to Aerojet Rocketdyne as the prime with major subcontractor ZIN Technologies and VACCO Industries. Management of the contract is being led by the NASA Glenn Research Center. Authorization to proceed for the contract was on May 16, 2016. In addition to the use of the AEPS development and hardware for ARRM the system is being considered for other mission applications. ${ }^{44}$

\section{G. Asteroid Redirect Vehicle Spacecraft Prime Contract}

The acquisition strategy, led by the Jet Propulsion Laboratory, leverages commercial spacecraft capabilities to reduce cost and risk for the ARV. Four companies were selected in this six-month initial phase for design studies for the ARV including: Boeing Phantom Works, Lockheed Martin Space Systems, Orbital ATK, and Space Systems/Loral. The second phase will competitively awarded for the development and implementation of the flight spacecraft bus by one of the study participants.

The conceptual ARV design requirements include the capability of xenon storage in excess of 5,000 kg. A xenon propellant load of 5 metric tons is almost $10 \%$ of the global annual production rate of xenon (currently estimated at 53 tons). ${ }^{45}$ A single procurement of this size with short-term delivery can disrupt the xenon market and drive up cost, which could make the propellant costs for the mission prohibitive. A multi-year strategy will be required for the acquisition of up to $5,000 \mathrm{~kg}$ of xenon without causing a spike in the xenon market price. ${ }^{45}$ 


\section{Conclusion}

The Ion Propulsion System for the Asteroid Redirect Robotic Mission as a Solar Electric Propulsion Technology Demonstration Mission is currently being developed focusing on the higher-risk and long-lead items. This work is a continuation of efforts initiated by NASA's Space Technology Mission Directorate several years ago. Collaborative HERMeS thruster and HP-120V PPU in-house developments conducted by NASA GRC and JPL have resulted in characterized high-fidelity laboratory hardware that proves the viability of the conceptual IPS for ARRM and provides demonstrated performance for mission design. Ongoing advanced technology work is focused on reducing the mission technical risks in a systematic, traceable approach. With some additional development the thruster and PPU designs could become the basis of future flight NASA missions. An electric propulsion string procurement has been initiated that will develop engineering-model hardware with an option for qualification and flight strings that will meet the ARRM requirements and support the target launch date.

\section{Acknowledgments}

The authors would like to like to thank the Space Technology Mission Directorate through the Solar Electric Propulsion Technology Demonstration Mission Project for funding the joint NASA GRC and JPL development of the Ion Propulsion System. Special thanks to Luis Pinero for providing valuable inputs on the HP-120V PPU design and description and to Tom Tomsik for providing xenon feed system schematics. The authors would also like to thank David Manzella, John Brophy, David Jacobson, Robert Jankovsky, and Tom Randolph for providing their expertise and technical guidance to the development of the Ion Propulsion Subsystem.

\section{References}

${ }^{1}$ Smith, B. K., Nazario, M. L., and Cunningham, C. C., "Solar Electric Propulsion Vehicle Demonstration to Support Future Space Exploration Missions," Space Propulsion 2012, Bordeaux, France, May 7-10, 2012.

2"NASA's Journey to Mars " NP-2015-08-2018-HQ, http:/www.nasa.gov/sites/default/files/atoms/files/journey-tomars-next-steps-20151008_508.pdf, 2015.

${ }^{3}$ Manzella, D. H. and Hack, K., "High-Power Solar Electric Propulsion for Future NASA Missions," AIAA-2014-3718, 50th AIAA/ASME/SAE/ASEE Joint Propulsion Conference, Cleveland, OH, July 28-30, 2015.

${ }^{4}$ Kamhawi, H., et al., "Overview of the Development of the Solar Electric Propulsion Technology Demonstration Mission 12.5-kW Hall Thruster," AIAA-2014-3898, 50th AIAA/ASME/SAE/ASEE Joint Propulsion Conference, Cleveland, OH, July 2830, 2014.

${ }^{5}$ Spence, B., et al., "Technology Maturation and Advancement Update of the ROSA/MegaROSA Solar Array " Huntington Beach, CA, May 7, 2014.

${ }^{6}$ Mercer, C. R. and et. al., "Solar Array Technology Development for Electric Propulsion," Huntington Beach, CA, May 11-14, 2015.

${ }^{7}$ Murphy, D., et al., "MegaFlex Solar Array Development and Test - Results from Phase 1 of the NASA Game Changing Development (GCD) Program for Solar Electric Propulsion (SEP) Solar Array Systems (SAS) Program," Huntington Beach, CA, May 7, 2014.

${ }^{8}$ Kerslake, T. W., "Advanced Solar Arrays for NASA Electric Propulsion Missions," SciTech 2015, Kissimmee, FL, January 5-9, 2015.

${ }^{9}$ Brophy, J. R. and Muirhead, B., "Near-Earth Asteroid Retrieval Mission (ARM) Study," IEPC-2013-82, 33rd International Electric Propulsion Conference, Washington, DC, Oct. 6 - 10, 2013.

${ }^{10}$ Gates, M., "NASA's Asteroid Redirect Mission Concept Development Summary," IEEE Aerospace Conference, Big Sky, MT, March 7-14, 2015.

${ }^{11}$ Muirhead, B. and Brophy, J. R., "Asteroid Redirect Robotic Mission Feasibility Study," 10.1109/AERO.2014.6836358, 2014 IEEE Aerospace Conference, Big Sky, MT, March 1-8, 2014.

${ }^{12}$ Mazanek, D. D., et al., "Asteroid Redirect Robotic Mission: Boulder Capture Overview Option," AIAA-2014-4432, AIAA SPACE 2014 Conference and Exposition, San Diego, CA, Aug. 4-7, 2014.

${ }^{13}$ Strange, N., et al., "Overview of Mission Design for NASA Astreroid Redirect Robotic Mission Concept," IEPC-2013321, 33rd International Electric Propulsion Conference, Washington, DC, Oct. 6 - 10, 2013.

${ }^{14}$ Brinza, D., Wang, J., Polk, J. E., and Henry, M., "Deep Space 1 Measurements of Ion Propulsion Contamination," Journal of Spacecraft and Rockets, Vol. 38, No. 3, pp. 426-432, May-June, 2001.

${ }^{15}$ Herman, D. A., et al., "The Ion Propulsion System for the Solar Electric Propulsion Technology Demonstration Mission," IEPC-2015-008, 30th International Electric Propulsion Conference, Kobe, Hyogo, Japan, July 4 - 10, 2015.

${ }^{16}$ Snyder, J. S., et al., "Vibration Test of a Breadboard Gimbal for the NEXT Ion Engine," AIAA-2006-4665, 42 ${ }^{\text {nd }}$ AIAA/ASME/SAE/ASEE Joint Propulsion Conference and Exhibit, Sacramento, CA, July 9-12, 2006.

${ }^{17}$ Vaughan, D. A., "Gimbal Development for the NEXT Ion Propulsion System," AIAA-2005-3865, 41 ${ }^{\text {st }}$ AIAA/ASME/SAE/ASEE Joint Propulsion Conference and Exhibit, Tucson, AZ, July 10-13, 2005. 
${ }^{18}$ Brophy, J. R., "Technology for a Robotic Asteroid Redirect Mission," 10.1109/AERO.2014.6836392, 2014 IEEE Aerospace Conference, Big Sky, MT, March 1-8, 2014.

${ }^{19}$ Hofer, R. R., et al., "Design Methodology and Scaling of the $12.5 \mathrm{~kW}$ HERMeS Hall Thruster for the Solar Electric Propulsion Technology Demonstration Mission," Presented at the 62nd JANNAF Propulsion Meeting, Nashville, TN, June 1-5, 2015.

${ }^{20}$ Mikellides, I., Hofer, R. R., Katz, I., and Goebel, D. M., "Magnetic Shielding of Hall Thrusters at High Discharge Voltages," Journal of Applied Physics, Vol. 116, No. 5, 053302, 2014.

${ }^{21}$ Kamhawi, H., Manzella, D. H., Smith, T. B., and Schmidt, G. R., "High-Power Hall Propulsion Development at NASA Glenn Research Center," Space Propulsion 2012, Bordeaux, France, May 7-10, 2012.

${ }^{22}$ Lopez Ortega, A., Mikellides, I., and Katz, I., "Hall2de Numerical Simulations for the Assessment of Pole Erosion in a Magnetically-Shielded Hall Thruster," IEPC-2015-249, 30th International Electric Propulsion Conference, Kobe, Hyogo, Japan, July 4 - 10, 2015.

${ }^{23}$ Kamhawi, H., Haag, T. W., Huang, W., and Hofer, R. R., "The Voltage-Current Characteristics of the 12.5 kW Hall Effect Rocket with Magnetic Shielding at Different Background Pressure Conditions," Presented at the 62nd JANNAF Propulsion Meeting, Nashville, TN, June 1-5, 2015.

${ }^{24}$ Kamhawi, H., et al., "Performance Characterization of the Solar Electric Propulsion Technology Demonstration Mission 12.5-kW Hall Thruster," IEPC-2015-007, 30th International Electric Propulsion Conference, Kobe, Hyogo, Japan, July 4 - 10, 2015.

${ }^{25}$ Hofer, R. R., et al., "Development Approach and Status of the $12.5 \mathrm{~kW}$ HERMeS Hall Thruster for the Solar Electric Propulsion Technology Demonstration Mission," IEPC-2015-186, 30th International Electric Propulsion Conference, Kobe, Hyogo, Japan, July 4 - 10, 2015.

${ }^{26}$ Shastry, R., Huang, W., and Kamhawi, H., "Near-Surface Plasma Characterization of the 12.5-kW NASA TDU1 Hall Thruster," AIAA-2015-3919, 51st AIAA/SAE/ASEE Joint Propulsion Conference, Orlando, FL, July 27 - $29,2015$.

${ }^{27}$ Huang, W., et al., "Non-Contact Thermal Characterization of NASA's 12.5-kW Hall Thruster," AIAA-2015-3920, 51st AIAA/SAE/ASEE Joint Propulsion Conference, Orlando, FL, July 27 - 29, 2015.

${ }^{28}$ Myers, J., Kamhawi, H., Yim, J., and Clayman, L., "Hall Thruster Thermal Modeling and Test Data Correlation," 52 ${ }^{\text {nd }}$ AIAA/SAE/ASEE Joint Propulsion Conference, Salt Lake City, UT, July 25-27, 2016.

${ }^{29}$ Katz, I., et al., "Effect of Solar Array Plume Interactions on Hall Thruster Cathode Common Potentials," $14^{\text {th }}$ Spacecraft Charging Technology Conference, Noordwijk, Netherlands, April 2016.

${ }^{30}$ Williams, G. J., et al., "Wear Testing of the HERMeS Thruster," 52 ${ }^{\text {nd }}$ AIAA/SAE/ASEE Joint Propulsion Conference, Salt Lake City, UT, July 25-27, 2016.

${ }^{31}$ Peterson, P. Y., Kamhawi, H., Williams, G. J., and Gilland, J. H., "NASA's HERMeS Hall Thruster Electrical Configuration Characterization," 52 ${ }^{\text {nd }}$ AIAA/SAE/ASEE Joint Propulsion Conference, Salt Lake City, UT, July 25-27, 2016.

${ }^{32}$ Kamhawi, H., et al., "Performance, Stability, and Pressure Effects Characterization Tests of NASA's 12.5-kW Hall Effect Rocket with Magnetic Shielding (HERMeS) Thruster," 52 ${ }^{\text {nd }}$ AIAA/SAE/ASEE Joint Propulsion Conference, Salt Lake City, UT, July 25-27, 2016.

${ }^{33}$ Huang, W., Kamhawi, H., and Haag, T. W., "Plasma Oscillation Characterization of NASA's HERMeS Hall Thruster via High Speed Imaging," 52 ${ }^{\text {nd }}$ AIAA/SAE/ASEE Joint Propulsion Conference, Salt Lake City, UT, July 25-27, 2016.

${ }^{34}$ Huang, W., Kamhawi, H., and Haag, T. W., "Facility Effect Characterization Test of NASA's HERMeS Hall Thruster," 52 ${ }^{\text {nd }}$ AIAA/SAE/ASEE Joint Propulsion Conference, Salt Lake City, UT, July 25-27, 2016.

${ }^{35}$ Hofer, R. R., et al., "The $12.5 \mathrm{~kW}$ HERMeS Hall thruster for the Asteroid Redirect Robotic Mission," 52 ${ }^{\text {nd }}$ AIAA/SAE/ASEE Joint Propulsion Conference, Salt Lake City, UT, July 25-27, 2016.

${ }^{36}$ Gilland, J. H., Williams, G. J., Burt, J. M., and Yim, J., "Carbon Back Sputter Modeling for Hall Thruster Testing," $52^{\text {nd }}$ AIAA/SAE/ASEE Joint Propulsion Conference, Salt Lake City, UT, July 25-27, 2016.

${ }^{37}$ Conversano, R., et al, "Performance Comparison of the $12.5 \mathrm{~kW}$ HERMeS Hall Thruster Technology Demonstration Units," 52 ${ }^{\text {nd }}$ AIAA/SAE/ASEE Joint Propulsion Conference, Salt Lake City, UT, July 25-27, 2016.

${ }^{38}$ Verhey, T. R., et al., "Hollow Cathode Assembly Development for the HERMeS Hall Thruster," 52 ${ }^{\text {nd }}$ AIAA/SAE/ASEE Joint Propulsion Conference, Salt Lake City, UT, July 25-27, 2016.

${ }^{39}$ Polk, J. E., Guerrero, P., Lopez Ortega, A., and Mikellides, I., "Hollow Cathode Operation with Time-Varying Currents," 52 ${ }^{\text {nd }}$ AIAA/SAE/ASEE Joint Propulsion Conference, Salt Lake City, UT, July 25-27, 2016.

${ }^{40}$ Goebel, D. M. and Polk, J. E., "Lanthanum Hexaboride Hollow Cathode Performance and Wear Testing for the ARRM Hall Thruster," 52 ${ }^{\text {nd }}$ AIAA/SAE/ASEE Joint Propulsion Conference, Salt Lake City, UT, July 25-27, 2016.

${ }^{41}$ Santiago, W., et al., "High Input Voltage, Power Processing Unit Performance Demonstration," 52 ${ }^{\text {nd }}$ AIAA/SAE/ASEE Joint Propulsion Conference, Salt Lake City, UT, July 25-27, 2016.

${ }^{42}$ Pinero, L. R., et al., "Development of High-Power Hall Thruster Power Processing Units at NASA GRC," AIAA-20153921, 51st AIAA/SAE/ASEE Joint Propulsion Conference, Orlando, FL, July 27 - 29, 2015.

43"Solicitation Number: NNC15ZCH014R," https://prod.nais.nasa.gov/cgibin/eps/synopsis.cgi?acqid=165360, 2015.

${ }^{44}$ Snyder, J. S., et al., "Additional Mission Applications for NASA’s 13.3-kW Ion Propulsion System," 2016 IEEE Aerospace Conference, Big Sky, MT, March 5-12, 2016.

${ }^{45}$ Herman, D. A. and Unfried, K. G., "Xenon Acquisition Strategies for High-Power Electric Propulsion NASA Missions," Presented at the 62nd JANNAF Propulsion Meeting, Nashville, TN, June 1-5, 2015. 